\title{
Cannabis use in adolescence and risk for adult psychosis: longitudinal prospective study
}

\author{
Louise Arseneault, Mary Cannon, Richie Poulton, Robin Murray, Avshalom Caspi, Terrie E Moffitt
}

Editorial by Rey and Tennant

Papers pp 1195,

1199

SGDP Research Centre, King's

College, London

SE5 8AF

Louise Arseneault

lecturer

Avshalom Caspi

professor

Terrie E Moffitt

professor

Division of

Psychological

Medicine, King's

College

Mary Cannon

Wellcome Trust

advanced fellow

Robin Murray

professor

Dunedin

Multidisciplinary

Health and

Development

Research Unit,

University of Otago,

Dunedin,

New Zealand

Richie Poulton

director, Dunedin

multidisciplinary

health and

development study

Correspondence to:

T E Moffitt

t.moffitt@

iop.kcl.ac.uk

BMJ 2002;325:1212-3
The strongest evidence that cannabis use may be a risk factor for later psychosis comes from a Swedish cohort study which found that heavy cannabis use at age 18 increased the risk of later schizophrenia sixfold. ${ }^{12}$ This study could not establish whether adolescent cannabis use was a consequence of pre-existing psychotic symptoms rather than a cause. We present the first prospective longitudinal study of adolescent cannabis use as a risk factor for adult schizophreniform disorder, taking into account childhood psychotic symptoms ${ }^{3}$ antedating cannabis use.

\section{Methods and results}

The Dunedin multidisciplinary health and development study (a study of a general population birth cohort of 1037 individuals born in Dunedin, New Zealand, in $1972-3)^{4}$ has a $96 \%$ follow up rate at age 26 . It obtained information on psychotic symptoms at age 11 and drug use at ages 15 and 18 from self reports and assessed psychiatric symptoms at age 26 with a standardised interview schedule to obtain DSM-IV (diagnostic and statistical manual of mental disorders, 4th edition) diagnoses. We analysed data from a representative group of 759 (74\%) living study members who had complete data on adult psychiatric outcomes, adolescent use of illicit substances, and childhood psychotic symptoms.
We divided the sample into three groups based on cannabis use at ages 15 and 18. The 494 controls (65.1\% of the sample) had reported using cannabis "never" or "once or twice" at both ages; cannabis users by age $18(236 ; 31.1 \%)$ first reported using cannabis "three times or more" at age 18; and cannabis users by age $15(29 ; 3.8 \%)$ had reported using cannabis "three times or more" at age 15 (all of whom continued to use cannabis at age 18).

Psychiatric outcomes at age 26 were symptoms of schizophrenia and depression and diagnoses of schizophreniform disorder and depression.

Multiple linear regression analyses showed that cannabis users by age 15 and by age 18 had more schizophrenia symptoms than controls at age 26 (table). These results remained significant after psychotic symptoms at age 11 were controlled for. The effect was stronger with earlier use.

Logistic regression analyses showed that people who used cannabis by age 15 were four times as likely to have a diagnosis of schizophreniform disorder at age 26 than controls. After psychotic symptoms at age 11 were controlled for, the risk for adult schizophreniform disorder remained higher among those who used cannabis at age 15 ; however, this risk was reduced by $31 \%$ and was no longer significant.

Cannabis use by age 15 did not predict depressive outcomes at age 26 . Use of other drugs in adolescence

Association between cannabis use in adolescence and schizophrenia and depressive symptoms and disorders at age 26 ( $n=759$ ), controlling for childhood psychotic symptoms and use of other drugs in adolescence

\begin{tabular}{|c|c|c|c|c|c|c|c|c|c|}
\hline \multirow[b]{3}{*}{ Model } & \multirow[b]{3}{*}{ Predictor } & \multicolumn{4}{|c|}{ Schizophrenia outcomes } & \multicolumn{4}{|c|}{ Depression outcomes } \\
\hline & & \multicolumn{2}{|c|}{$\begin{array}{l}\text { Schizophrenia symptoms } \\
\text { (scores 0-58) }\end{array}$} & \multicolumn{2}{|c|}{$\begin{array}{l}\text { Schizophreniform disorder } \\
(\mathrm{n}=25 ; 3.3 \%)\end{array}$} & \multicolumn{2}{|c|}{$\begin{array}{l}\text { Depressive symptoms } \\
\text { (scores 0-54) }\end{array}$} & \multicolumn{2}{|c|}{$\begin{array}{c}\text { Depressive disorder ( } \mathrm{n}=118 ; \\
15.5 \%)\end{array}$} \\
\hline & & BП (SE) & $P$ value & Odds ratio $(95 \% \mathrm{CI})$ & $P$ value & $\mathrm{B} \S(\mathrm{SE})$ & $P$ value & Odds ratio $(95 \% \mathrm{Cl})$ & $P$ value \\
\hline \multirow[t]{2}{*}{$1 \dagger$} & $\begin{array}{l}\text { Cannabis users by age } \\
15\end{array}$ & $6.91(0.91)$ & 0.001 & 4.50 (1.11 to 18.21$)$ & 0.035 & $0.25(1.93)$ & 0.897 & 1.02 (0.34 to 3.04$)$ & 0.971 \\
\hline & $\begin{array}{l}\text { Cannabis users by age } \\
18\end{array}$ & $1.04(0.40)$ & 0.009 & 1.65 (0.65 to 4.18$)$ & 0.293 & $1.98(0.84)$ & 0.018 & 1.62 (1.06 to 2.49) & 0.028 \\
\hline \multirow[t]{4}{*}{$2 \ddagger$} & $\begin{array}{l}\text { Weak psychotic } \\
\text { symptoms at age } 11\end{array}$ & $0.68(0.53)$ & 0.201 & 4.65 (1.84 to 11.78$)$ & 0.001 & $1.60(1.13)$ & 0.159 & $1.45(0.82$ to 2.56$)$ & 0.203 \\
\hline & $\begin{array}{l}\text { Strong psychotic } \\
\text { symptoms at age } 11\end{array}$ & $5.16(1.39)$ & 0.001 & 15.97 (3.38 to 75.47 ) & 0.001 & $-0.55(2.96)$ & 0.852 & $0.54(0.07$ to 4.25$)$ & 0.554 \\
\hline & $\begin{array}{l}\text { Cannabis users by age } \\
15\end{array}$ & $6.56(0.91)$ & 0.001 & 3.12 (0.73 to 13.29$)$ & 0.124 & $0.13(1.94)$ & 0.946 & 1.01 (0.34 to 3.02$)$ & 0.987 \\
\hline & $\begin{array}{l}\text { Cannabis users by age } \\
18\end{array}$ & $1.03(0.39)$ & 0.009 & $1.42(0.54$ to 3.74$)$ & 0.473 & $1.96(0.84)$ & 0.020 & 1.61 (1.05 to 2.47 ) & 0.031 \\
\hline \multirow{3}{*}{$\begin{array}{l}0 \\
\mathrm{a} \\
0 \\
1 \\
0 \\
1\end{array}$} & $\begin{array}{l}\text { Other drug users at } \\
\text { age } 15 \text { to } 18\end{array}$ & $-0.3(0.69)$ & 0.615 & $0.30(0.05$ to 1.62$)$ & 0.160 & $2.48(1.45)$ & 0.086 & 1.23 (0.55 to 2.32$)$ & 0.743 \\
\hline & $\begin{array}{l}\text { Cannabis users by age } \\
15\end{array}$ & $7.2(1.07)$ & 0.001 & 11.38 (1.84 to 70.45$)$ & 0.009 & $-1.75(2.26)$ & 0.438 & $0.93(0.27$ to 3.17$)$ & 0.905 \\
\hline & $\begin{array}{l}\text { Cannabis users by age } \\
18\end{array}$ & $1.1(0.42)$ & 0.008 & 1.95 (0.76 to 5.01$)$ & 0.167 & $1.55(0.88)$ & 0.078 & 1.59 (1.01 to 2.49$)$ & 0.043 \\
\hline
\end{tabular}

*Model 1 includes the effects of adolescent cannabis use only; model 2 adds to model 1 controls for childhood psychotic symptoms; model 3 adds to model 1 controls for other drug use.

†Estimates for each step are given controlling for socioeconomic status and sex. The socioeconomic status of study members' families was coded into one of six categories based on educational level and income associated with occupations in New Zealand. The scale ranges from 1=unskilled labourer to $6=$ professional and reflects the average of the highest status of either parent across the seven assessments of the Dunedin study from birth through to age 15 .

tWhen study members were aged 11, five questions about psychotic symptoms were asked during the interview and were then scored by a psychiatrist $(0=n 0 ;$ $1=y e s$, likely; $2=y e s$, definitely). Individuals reporting weak psychotic symptoms at age 11 (94 (12.4\%) with score of 1$)$ and those reporting strong symptoms (12 $(1.6 \%)$ with score of $\geqslant 2)$ were compared with individuals who reported no symptoms at all $(653(86.0 \%))$.

$\S$ Comparison for other drug users at age 15 to $18(78 ; 10.3 \%)$ was made with individuals who reported "never" using other drugs at ages 15 and 18 (681; $89.7 \%)$. Other drugs refer to substances such as glue, cocaine, and opiates.

IConfidence intervals for regression coefficients (B) can be calculated using the standard error of the estimate, based on the formula: $B \pm\left(1.96{ }^{*} S E\right)$. 
did not predict schizophrenia outcomes over and above the effect of cannabis use.

\section{Comment}

Using cannabis in adolescence increases the likelihood of experiencing symptoms of schizophrenia in adulthood. Our findings agree with those of the Swedish study ${ }^{1}$ and add three new pieces of evidence. Firstly, cannabis use is associated with an increased risk of experiencing schizophrenia symptoms, even after psychotic symptoms preceding the onset of cannabis use are controlled for, indicating that cannabis use is not secondary to a pre-existing psychosis. Secondly, early cannabis use (by age 15) confers greater risk for schizophrenia outcomes than later cannabis use (by age 18). The youngest cannabis users may be most at risk because their cannabis use becomes longstanding. Thirdly, risk was specific to cannabis use, as opposed to use of other drugs, and early cannabis use did not predict later depression. Our findings now require replication in large population studies with detailed measures of cannabis use and schizophrenia.

Although most young people use cannabis in adolescence without harm, a vulnerable minority experience harmful outcomes. A tenth of the cannabis users by age 15 in our sample (3/29) developed schizophreniform disorder by age 26 compared with 3\% of the remaining cohort (22/730). Our findings suggest that cannabis use among psychologically vulnerable adolescents should be strongly discouraged by parents, teachers, and health practitioners. Policy makers and law makers should concentrate on delaying onset of cannabis use.

We thank the Dunedin study members, data managers HonaLee Harrington and Barry Milne, study founder Phil Silva, and Air New Zealand. Helpful comments on earlier drafts were provided by Griffith Edwards.

Contributors: LA participated in the study design, analysed and interpreted the data, and wrote the first draft of the paper. MC and RP participated in the study design and assisted with the analysis and interpretation of the data and the writing of the paper. RM, AC, and TEM participated in the study design and assisted with the interpretation of the data and writing of the paper. RP, AC, and TEM coordinated the collection of the data. LA, RP, and TEM are guarantors of the study.

Funding: The Dunedin Multidisciplinary Health and Development Research Unit and RP are supported by the New Zealand Health Research Council. This research received support from the Schizophrenia Research Fund, London (MC, AC, TEM), the UK Medical Research Council, the EJLB Foundation (MC) and from US-NIMH grants MH45070 (TEM) and MH49414 (AC). LA is supported by the Canadian Institute of Health Research. TEM is a Royal Society-Wolfson Merit Award holder.

Competing interests: None declared.

1 Andréasson S, Allebeck P, Engström A, Rydberg U. Cannabis and schizophrenia: a longitudinal study of Swedish conscripts. Lancet 1987;ii:1483-5.

2 Strang J, Witton J, Hall W. Improving the quality of the cannabis debate: defining the different domains. BMJ 2000;320:108-10.

3 Poulton R, Caspi A, Moffitt TE, Cannon M, Murray RM, Harrington H. Children's self-reported psychotic symptoms and adult schizophreniform disorder: a 15-year longitudinal study. Arch Gen Psychiatry 2000;57:1053-8

4 Silva PA, Stanton WR, eds. From child to adult:the Dunedin multidisciplinar health and development study. Auckland: Oxford University Press, 1996.

5 Fergusson DM, Horwood LJ. Early onset cannabis use and psychosocial adjustment in young adults. Addiction 1997;92:279-96.

\section{Drug points}

\section{Antibody deficiency associated with carbamazepine}

G Hayman, A Bansal

A 45 year old woman was referred to our immunology department with antibody deficiency and an eight month history of recurrent upper respiratory tract infections that required antibiotic therapy. Four years previously she was diagnosed as having epilepsy and was treated with carbamazepine. Serum immunoglobulins were measured repeatedly and showed antibody deficiency (IgG $4.5 \mathrm{~g} / 1$ (range 6-16 g/1), IgM $0.3 \mathrm{~g} / 1$ (0.5-2 g/1), and IgA $0.67 \mathrm{~g} / 1$ (0.8-2.8 g/l)). Lymphocyte immunophenotyping and specific antibody production to tetanus toxoid, Haemophilus influenzae type B, and Pneumovax II vaccines were normal. In view of her recurrent infections she was treated with prophylactic oral antibiotics and her condition was monitored over several months. She stopped taking carbamazepine and three months later her IgG had increased to within the reference range (IgG $6.1 \mathrm{~g} / \mathrm{l}$, IgM $0.22 \mathrm{~g} / \mathrm{l}$, and $\operatorname{IgA} 0.74 \mathrm{~g} / \mathrm{l})$. By seven months the serum immunoglobulins were virtually normal (IgG $7.5 \mathrm{~g} / 1$, IgM $0.33 \mathrm{~g} / \mathrm{l}$, and $\operatorname{IgA} 0.89 \mathrm{~g} / \mathrm{l})$. At this point she had improved clinically with no active infections, and prophylactic antibiotics were discontinued without incident.

Antibody deficiency is a recognised, but rare, adverse effect associated with the use of carbamazepine, although the prevalence of this complication is unknown. The Committee on Safety of Medicines ADROIT database lists nine cases of hypogammaglobulinaemia or $\gamma$ globulin abnormality related to the use of carbamazepine (R. Granados, personal communication) and a handful of case reports have been published on the subject. ${ }^{1-3}$ The British National Formulary does not, however, mention antibody deficiency as an adverse effect of carbamazepine. Many of the other cases report associated skin rashes. It is not known how many patients using carbamazepine develop symptomatic or asymptomatic antibody deficiency, compared with the total number using the drug, or how long it takes for antibody deficiency to develop or resolve. Similar antibody deficiency has been reported in association with the use of phenytoin, although isolated IgA deficiency is far more common with this drug. ${ }^{4}$

Patients requiring carbamazepine should have serum immunoglobulins measured if they experience recurrent or persistent infections. At present, the apparent rarity of carbamazepine related antibody deficiency precludes routine serum immunoglobulin assessment.

Funding: None.

Competing interests: None declared.

1 Van Ginnekin EE, van der Meer JW, Netten PM. A man with a mysteriou hypogammaglobulinaemia and skin rash. Neth J Med 1999;54:158-62.

2 Spickett GP, Gompels MM, Saunders PW. Hypogammaglobulinaemia with absent B lymphocytes and agranulocytosis after carbamazepine treatment. J Neurol Neurosurg Psychiatry 1996;60(4):459.

3 Garcia Rodriguez MC, de la Concha EG, Fontan G, Pascal-Salcedo D, Fernandez J, Ojeda JA, et al. Transient hypogammaglobulinaemia in the adult. Functional assessment of T and B lymphocytes. J Clin Lab Immuno 1983;11(1):55-8

4 Hammarstrom L, Smith CIE. Genetic approach to common variable immunodeficiency and IgA deficiency. In: Ochs HD, Smith CI, Puck JM, eds. Primary immunodeficiency diseases. New York: Oxford University Press, 1999:250-62. 